\title{
COMPARATIVE REMOVAL OF METHYLENE BLUE FROM AQUEOUS SOLUTION USING DIFFERENT ADSORBENTS
}

\author{
IKHLASS MARZOUK TRIFI ${ }^{a^{*}}$, BEYRAM TRIFI $^{b}$, HOUDA ZENDAH $^{c}$ AND BÉCHIR HAMROUNI ${ }^{a}$ \\ ${ }^{a}$ Université de Tunis El Manar, Faculté des Sciences de Tunis, Laboratoire Dessalement et Traitement des Eaux, 2092, Tunisie. \\ ${ }^{b}$ Laboratoire Matériaux, Traitement et Analyse, Institut National de Recherche et d'Analyse Physico-chimique (INRAP), Biotechpole Sidi Thabet, Tunisie. \\ ${ }^{c}$ Laboratoire de Traitement des Eaux Naturelles, Centre de Recherches et des Technologies des Eaux, Technopole de Borj-Cédria, Soliman, Tunisie.
}

\begin{abstract}
A comparative study for the adsorption of Methylene blue onto different prepared adsorbents was investigated. First, a comparative study was performed with different parameters between orange peels, orange peels activated with phosphoric acid, orange peels activated encapsulating in alginate and orange peels activated encapsulating in magnetic alginate. It can be concluded that the magnetic alginate composite beads were the best adsorbent. Then the isotherms, kinetics and regeneration studies for the removal of Methylene blue were studied onto magnetic alginate composite beads. The adsorption of Methylene blue on magnetic alginate composite beads was applied to isotherm models showed that the interaction of Methylene blue with magnetic alginate composite beads surface is localized monolayer adsorption. The kinetic process flow a pseudo-second-order kinetic. Finally, the removal efficiencies were maintained using $\mathrm{HCl}$ solution as desorbing agent after five cycles of adsorption-desorption.
\end{abstract}

Keywords: Activated orange peels; isotherms; kinetics; magnetic alginate composite beads; methylene blue.

\section{INTRODUCTION}

In recent decades, orange production has increased significantly. The orange are utilized in industrial manufacturing of juice, many of the orange peels are discarded in the garbage in great amounts and represent a serious problem to the environment. To reduce this phenomena and contribute to have a clean environment, orange peels are used for the production of low cost and effective adsorbents in adsorption processes to reduce the pollution of water. The simultaneous existence of many types of pollutants such as dyes, pesticides and pharmaceuticals in aqueous cause serious problems for human. Due to their abusive use in the textile, medicinal, cosmetic and other industries, the presence of dyes in aquatic environment has been very destructive [1,2]. The difficulty for removing dyes is due to their stability and very complex aromatic structures [3]. Several physical and chemical methods are used to remove dyes from polluted water such as photocatalysis [4], biological degradation [5], coagulationflocullation [6], chemical oxidation [7], reverse osmosis [8] and adsorption [9]. Adsorption is considered to be the most effective technology, because of simplicity of design and low cost. Several materials were successfully used in processes of discoloration of water such as biopolymer, composites clay-alginate $[2,10]$ and chitosan [11]. Many cheap materials derived from wastes of biomass were prepared and used in the removal of dyes $[12,13]$. These are less expensive and renewable precursors compared to the commercial activated carbon [14]. However, these powdered adsorbents have problems in their separation from the solution to be treated, they are difficult to regenerate and therefore their use can be limited [15]. In order to provide a very efficient solution and to improve the value of these materials, their powder is converted into beads by encapsulating them in alginate. The adsorption and gelling properties of alginate make it possible to consider the combination of adsorbents by encapsulation and the production of materials that can be used in water treatment processes [16,17]. An innovative technology that has gained attention is the use of magnetic materials. Magnetic separation is now widely used in the fields of medicine, diagnostics, molecular biology [18], bioinorganic chemistry and catalysis [19]. Magnetic separation is considered a new technique for water treatment and environmental decontamination. This technique has the advantage of producing no contaminants and has the capacity to treat a large quantity of wastewater in a short time [20]. One of the most important advantages is the ease of separation from treated water through an external magnetic field in a short time. Many studies have reported on removing dyes [21,22] using magnetic chitosan composite adsorbents and magnetic alginate composite adsorbents [23]. The aim of this work was first the comparison the removal of Methylene blue by adsorption using adsorbent as orange peels and orange peels activated by phosphoric acid, Activated Orange Peels encapsulated in alginate and incorporating magnetite nanoparticles $\left(\mathrm{Fe}_{2} \mathrm{O}_{3}\right)$ into the alginate beads. Finally, the isotherms, kinetics and regeneration studies for the removal of Methylene blue were investigated for the best adsorbent.

\section{EXPERIMENTAL}

\section{Preparation of adsorbents}

Orange peels were washed with tap water to eliminate dust and other residues and dried. They were crushed in small particles and washed again with distilled water several times until the disappearance of odour and obtaining clear flushing water. It was dried during 24 hours at temperature of $110{ }^{\circ} \mathrm{C}$ in a drying oven, crushed and then it was sieved to have powder with homogenous particle. The raw material obtained was noted OP. It was used for preparation of all new adsorbents. Phosphoric acid activated OP was done according procedure given in the literature [24]. Briefly, $2 \mathrm{~g}$ of powder OP were mixed with the phosphoric acid solution $\left(0.6 \mathrm{~mol} \mathrm{~L}^{-1}\right)$ in a beaker of $50 \mathrm{~mL}$. The mixture was stirred during 30 minutes at the room temperature; it was centrifuged and separated from the supernatant. It was dried in furnace at $60^{\circ} \mathrm{C}$ for $24 \mathrm{~h}$. The temperature of furnace was then climbed up to $120^{\circ} \mathrm{C}$ and drying was maintained during 90 minutes. The obtained product was washed several times with distilled water to eliminate the excessive acid which was tested by $0.1 \mathrm{~mol} \mathrm{~L}^{-1}$ of nitrate in the washing water. Product was dried later in furnace at $50{ }^{\circ} \mathrm{C}$ for $24 \mathrm{~h}$. It was named Activated Orange Peels (AOP); it was stocked in hermetic boxes for using in adsorption tests and preparation of composites beads.

\section{Preparation of composite beads: activated orange peels/ alginate beads}

Solution of sodium alginate (SA) of $2 \%(\mathrm{w} / \mathrm{v})$ was prepared. To this solution we added $2 \mathrm{~g}$ of AOP to form activated orange peels/alginate (AOP/A). The mixture was stirred for 1 hour. Then it was dropped into $4 \%(\mathrm{w} / \mathrm{v})$ calcium chloride under vigorous stirring to form beads referred as AOP/A. Beads were washed several times to ensure the removal excess of sodium chloride in beads and dried at room temperature.

\section{Preparation of magnetic material}

The magnetic material used was a ferrofluid composed of maghemite $(\delta$ $\mathrm{Fe}_{2} \mathrm{O}_{3}$ ) nanoparticles coated by citrate ions and dispersed in an aqueous solution. Particles were synthesized by coprecipitation of a stoechiometric mixture of ferrous and ferric chlorides in an ammonium hydroxide solution. The magnetite $\left(\mathrm{Fe}_{3} \mathrm{O}_{4}\right)$ precipitate obtained was acidified by nitric acid and oxidized into maghemite $\left(\delta-\mathrm{Fe}_{2} \mathrm{O}_{3}\right)$ at $90^{\circ} \mathrm{C}$ with iron (III) nitrate. To obtain a stable magnetic dispersion compatible with an alginate gel (neutral medium), particles were coated by citrate anions. After precipitation with acetone, coated particles were dispersed in water, then dried at room temperature and it was stocked in hermetic boxes for using in the preparation of AOP/MAs beads. 


\section{Preparation of Magnetic alginate composite Beads}

For the preparation of AOP/MA beads, $2 \mathrm{~g}$ of sodium alginate was dissolved in $100 \mathrm{~mL}$ of water, time we added $2 \mathrm{~g}$ of AOP for activated orange / alginate peels (AOP/A) to the solution; then, $2 \mathrm{~g}$ ferrofluide was dispersed in it, and the mixture was vigorously stirred for $2 \mathrm{~h}$ in a shaker. The viscous suspension was dripped into $\mathrm{CaCl}_{2}$ bath (4\%), and the composite beads Activated Orange Peels / Magnetic Alginate (AOP/MA). The magnetic alginate composite beads were separated from the solution using a magnet, washed three times by deionized water, and then stored in a deionized water bath for further use.

\section{Adsorbate and reagents}

The synthetic wastewater was prepared with distilled water and dye Methylene Blue. Methylene Blue $\left(\mathrm{C}_{16} \mathrm{H}_{18} \mathrm{~N}_{3} \mathrm{SCl}\right.$, M.W $\left.=319.86 \mathrm{~g} \mathrm{~mol}^{-1}, \lambda_{\max }=665 \mathrm{~nm}\right)$ was procured from Sigma Aldrich. In the adsorption experiments, the chemical with analytical reagent grade were used.

\section{Batch adsorption experiments}

Adsorption experiments were carried out in a batch system using Erlenmeyer flasks under magnetic stirring. Afterwards, all samples were centrifuged and filtered then the concentration of dyes was calculated from the measured absorbance at the maximum absorption wave length by means of an UV-Vis spectrophotometer. Dye removal percentage was calculated as follows Equation (1):

Dye Removal $\mathrm{Y} \%=\left(\mathrm{C}_{0}-\mathrm{C}_{\mathrm{e}}\right) / \mathrm{C}_{0} \times 100$

Where $\mathrm{C}_{0}$ and $\mathrm{C}_{\mathrm{e}}$ are the initial and equilibrium dye concentrations respectively.

\section{RESULTS AND DISCUSSION}

\section{Optimisation}

A study was performed with different parameters as adsorbent dose, $\mathrm{pH}$, and temperature in order to compare between the different adsorbents and to indicate the optimum of each parameter.

\section{Effect of adsorbent dose}

To optimize the adsorbent dose for the removal of MB from the solution, adsorption studies were carried out with initial concentration $10 \mathrm{mg} \mathrm{L}^{-1}$ of $\mathrm{MB}$ at $25^{\circ} \mathrm{C}$; with varying adsorbent doses 0.5 to $2.5 \mathrm{~g}$. The effect of adsorbent dose is shown in Figure 1. Results show that as the adsorbent dose is increased for MB, and achieves $58.4 \%$ for OP, $66.9 \%$ for AOP, $82 \%$ for AOP/A and 94\% AOP/ MA.

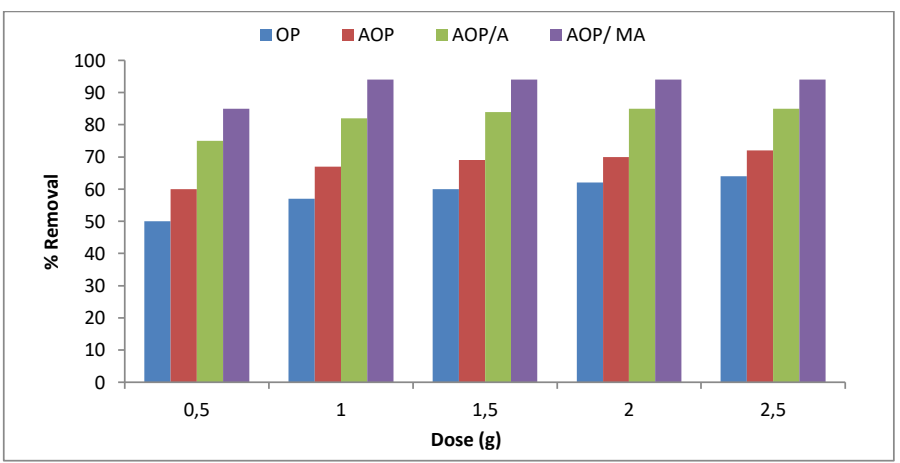

Figure 1. Effect of dose.

The improvement of removal from $58.4 \%$ for OP to $66.9 \%$ for AOP is due to increased available sorption surface and the availability of more adsorption sites [25]. In fact the use of OP in the form of powder on large scale is limited by process engineering difficulties such as dispersion, cost of regeneration and clogging of reactor which makes its use difficult in packed bed systems [26]. Moreover, powdered adsorbents are not recoverable and reusable through centrifugation or filtration, which in turns produce huge waste and create another problem for the environment [26]. The powder is converted into beads by encapsulating them in alginate which provides a very efficient solution for the regeneration and improving the removal to $82 \%$ for AOP/A. It can found that about $15.1 \%$ folds higher in case of immobilized AOP/A bead as compared to AOP powder. This can be attributed to the designed system, which offered a dispersed organization of AOP particles into a bead and avoided their agglomeration. The agglomeration of AOP particles reduces the effective surface area per unit volume as well as blocks [27]

One of the most used strategies consists of incorporating magnetite nanoparticles $\left(\mathrm{Fe}_{2} \mathrm{O}_{3}\right)$ into the alginate beads as the active magnetic part of the absorbent to allow for an easy separation and recovery of the beads from treated waters [28]. The removal of dye is $94 \%$ for AOP/MA this may be attributed to the increase in the availability of active sites resulting from the increased dose and also to the magnetically mixing who facilitate the adsorption of dye.

\section{Effect of pH}

The effect of $\mathrm{pH}$ was determined by studying adsorption of dyes with initial concentration $10 \mathrm{mg} \mathrm{L}^{-1}$ and $1 \mathrm{~g}$ per $100 \mathrm{~mL}$ for adsorbent over a $\mathrm{pH}$ range of 2-12 keeping the other parameters constants at $25^{\circ} \mathrm{C}$ during $180 \mathrm{~min}$. The adjustments of $\mathrm{pH}$ were used with adding $0.1 \mathrm{M} \mathrm{HCl}$ or $0.1 \mathrm{M} \mathrm{NaOH}$ in the solution of dye. The effect of $\mathrm{pH}$ on the adsorption of MB by OP, AOP, AOP/A and AOP/MA is shown in Figure 2.

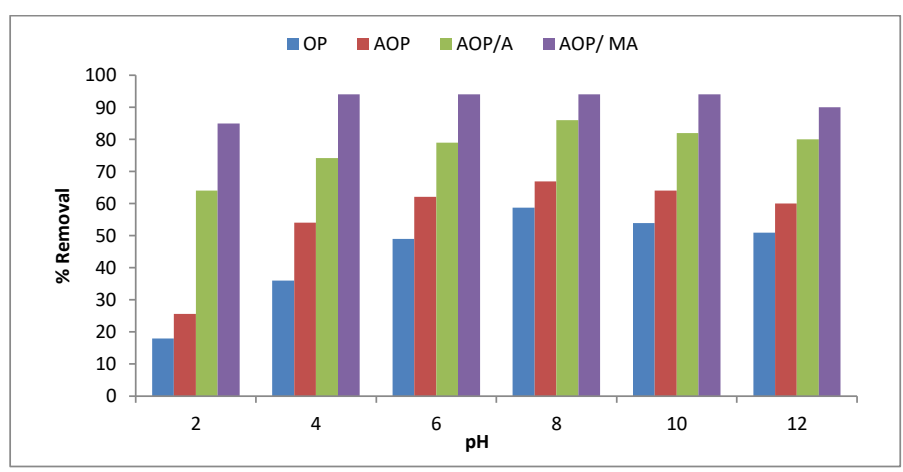

Figure 2. Effect of $\mathrm{pH}$.

In the Figure 2, the maximum removal of MB takes place about 8 to reach 58.8 $\%$ for OP, $66.9 \%$ for AOP, $86 \%$ for AOP/A and 94\% AOP/MA. In acidic $\mathrm{pH}$ the removal $\%$ decreases, it is probably due to the high presence of positively charged sites, which decreases the interaction of the MB (cationic dye) ions with the sites of the adsorbent and prevents the formation of bonds between the MB and the active site, due to the electrostatic repulsion and the competition between the $\mathrm{H}^{+}$ions and the cationic dye for adsorption sites [2]. At higher $\mathrm{pH}$, a decrease of removal for OP, AOP, AOP/A and AOP/MA due to the presence of $\mathrm{OH}^{-}$which makes competition with dyes [29]. Similar results were found by other authors $[15,30]$. Globally, the adsorption seems to be affected a little by the $\mathrm{pH}$ solution.

\section{Effect of temperature}

In order to study the effect of the temperature, the adsorption of MB was investigated for $15,25,35$ and $45^{\circ} \mathrm{C}$ with an initial dye concentration $10 \mathrm{mg} \mathrm{L}^{-1}$ and $1 \mathrm{~g} / 100 \mathrm{~mL}$ of OP, AOP, AOP/A and AOP/MA.

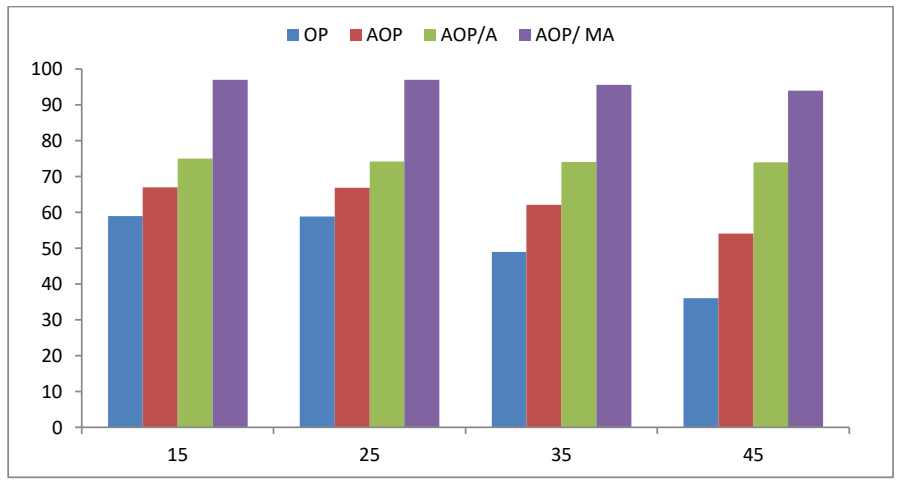

Fig 3. Effect of Temperature. 
The results in figure 3 show that the removal efficiency increased from $51 \%$ to OP, $60 \%$ for AOP, $80 \%$ AOP/A and $90 \%$ AOP/MA for MB with temperature increase from 15 to $45{ }^{\circ} \mathrm{C}$. The removal of the dye decreased with increasing temperature suggesting that adsorption of $\mathrm{MB}$ onto $\mathrm{OP}$ and $\mathrm{AOP}$ was an exothermic process. According to the result the increasing of temperature didn't affect the removal of MB onto AOP/A and AOP/MA. Similar results were found by other authors [31].

\section{Equilibrium adsorption isotherms}

The isotherms, kinetics and regeneration studies for the removal of Methylene blue were investigated to AOP/MA, seems to be the best adsorbent, according to the optimisation study. The equilibrium adsorption study was carried out with $100 \mathrm{~mL}$ of Methylene blue solution at $10 \mathrm{mg} \mathrm{L}^{-1}$, dose $1 \mathrm{~g}$ and at three temperatures 25 to $45^{\circ} \mathrm{C}$.

\section{Freundlich isotherms}

The Freundlich isotherm model is an empirical equation and it can be applied to multilayer adsorption. This model assumes that the surface of the adsorbent is heterogeneous and active sites and their energies distribute exponentially. The stronger binding sites are occupied first, until adsorption energy is exponentially decreased upon the completion of adsorption process [32]. The Freundlich isotherm is expressed as Equation (2):

$$
\log q_{e}=\log K+1 / n \log C_{e}
$$

where $\mathrm{K}$ indicates the adsorption capacity and $1 / \mathrm{n}$ is an arbitrary constant related to the adsorption intensity. $\mathrm{K}$ and $\mathrm{n}$ are empirical constants dependent on several environmental factors, and can be determined from the linear plot of log $\mathrm{q}_{\mathrm{e}}$ versus $\log \mathrm{C}_{\mathrm{e}}$. The results were indicated in the Table 1 .

\section{Langmuir isotherms}

The Langmuir isotherm is the simplest and still the most useful isotherm, for both physical and chemical adsorption. This model assumes that adsorption is limited to a monolayer: only a single layer of molecules on the adsorbent surface are absorbed, adsorbent surface is homogeneous and adsorption energy is uniform for all sites and there is no transmigration of adsorbate in the plane of the surface [32]. The Langmuir equation is given by Equation (3):

$$
1 / q_{\mathrm{e}}=1 / \mathrm{q}_{\mathrm{m}}+1 /\left(\mathrm{C}_{\mathrm{e}} \mathrm{q}_{\mathrm{m}} \mathrm{b}\right)
$$

where $\mathrm{C}_{\mathrm{e}}$ is the equilibrium dyes concentration $(\mathrm{mg} / \mathrm{L}), \mathrm{q}_{\mathrm{e}}$ the quantity of dyes adsorbed at equilibrium $\left(\mathrm{mg} \mathrm{g}^{-1}\right), \mathrm{q}_{\mathrm{m}}$ and $\mathrm{b}$ are constants related to the maximum adsorption capacity $\left(\mathrm{mg} \mathrm{g}^{-1}\right)$ and the $b$ is the equilibrium constant $\left(\mathrm{L} \mathrm{mg}^{-1}\right)$, which is a criterion of the tendency of the adsorbate to adsorb onto the active sites of the adsorbent surface.

The Langmuir constants $\mathrm{q}_{\mathrm{m}}$ and $\mathrm{b}$ can be determined from the plot of $1 / \mathrm{q}_{\mathrm{e}}$ versus $1 / C_{e}$ results in a straight line of slope $1 / q_{m}$ and an intercept of $1 / q_{m} b$. Alternatively, if adsorption followed Langmuir isotherm then a linear relationship would be obtained between $1 / \mathrm{q}_{\mathrm{e}}$ and $\mathrm{C}_{\mathrm{e}}$ from which the two constants $\mathrm{q}_{\mathrm{m}}$ and $\mathrm{b}$, could be calculated. The parameter $r$ was determined in order to predict the adsorption efficiency using the following Equation (4).

$$
\mathrm{r}=1 /\left(1+\mathrm{C}_{0} \mathrm{~b}\right)
$$

The values of $r$ indicated the type of Langmuir isotherm to be irreversible $(r=$ $0)$, favorable $(0<\mathrm{r}<1)$, linear $(\mathrm{r}=1)$ or unfavorable $(\mathrm{r}>1)$. The $r$ was indicated in the Table 1.

\section{Dubinin-Radushkevich isotherm}

The Dubinin-Radushkevich model was chosen to estimate the heterogeneity of the surface energies and also to determine the nature of adsorption processes as physical or chemical. The D-R sorption isotherm is more general than the Langmuir isotherm as its derivation is based on ideal assumptions such as equipotent of the sorption sites, absence of stoic hindrance between sorbed and incoming particles and surface homogeneity on microscopic level [33]. D-R isotherm is represented by Equation (5) below:

$$
\operatorname{Ln} \mathrm{q}_{\mathrm{e}}=\operatorname{Ln} \mathrm{q}_{\mathrm{s}}-\mathrm{B} \varepsilon^{2}
$$

where $\mathrm{q}_{\mathrm{s}}$ is the theoretical saturation capacity $\left(\mathrm{mol} \mathrm{g}^{-1}\right)$, B is a constant related to energy of adsorption per mole of the adsorbate $\left(\mathrm{mol}^{2} \mathrm{~J}^{-2}\right)$, and $\varepsilon$ is the Polanyi potential given by the relation Equation (6):

$$
\varepsilon=R T \operatorname{Ln}\left(1+1 / C_{e}\right)
$$

$\mathrm{C}_{\mathrm{e}}$ is the equilibrium concentration of dye $\left(\mathrm{mg} \mathrm{L}^{-1}\right), \mathrm{R}$ is the gas constant $\left(\mathrm{J} \mathrm{mol}^{-1} \mathrm{~K}^{-1}\right)$ and $\mathrm{T}$ is the absolute temperature $(\mathrm{K})$.

The $\mathrm{D}-\mathrm{R}$ constant can give the mean free energy of adsorption $\mathrm{E}=(2 \mathrm{~B})^{-0.5}$ $\left(\mathrm{kJ} \mathrm{mol}^{-1}\right)$ [33]. If $\mathrm{E}$ is between 8 and $16 \mathrm{~kJ} \mathrm{~mol}^{-1}$, the process is chemisorption, while for values of $\mathrm{E}<8 \mathrm{~kJ} / \mathrm{mol}$ suggests a physical process. The parameters obtained for different isotherms along with $\mathrm{R}^{2}$ value are presented in Table 1 .

\section{Temkin isotherms}

Temkin isotherm model takes into account the effects of indirect adsorbate/adsorbate interactions on the adsorption process. The Temkin isotherm is valid only for an intermediate range of ion concentrations. The Temkin linear form of isotherm [34] is given by Equation (7):

$$
\mathrm{q}_{\mathrm{e}}=\mathrm{B}_{1} \operatorname{LnA}+\mathrm{B}_{1} \operatorname{LnC}_{\mathrm{e}}
$$

where $\mathrm{B}_{1}$ is related to the heat of adsorption $\left(\mathrm{J} \mathrm{mol}^{-1}\right)$, $\mathrm{A}$ is the equilibrium binding constant $\left(\mathrm{L} \mathrm{mg}^{-1}\right)$. The Temkin isotherm contains a factor that explicitly takes adsorbing species-adsorbate interactions into account [34]. The adsorption heat of all the molecules in the layer would decrease linearly due to adsorbate/adsorbate interactions. The Temkin constants gathered in Table 1.

\section{Harkins-Jura isotherm}

Harkins-Jura isotherm model indicates a multilayer adsorption and the presence of heterogeneous pore. The linear mathematical form of Harkins-Jura isotherm is represented by Equation (8):

$$
1 / \mathrm{q}_{\mathrm{e}}^{2}=\mathrm{B}_{\mathrm{HJ}} / \mathrm{A}_{\mathrm{HJ}}-1 / \mathrm{A}_{\mathrm{HJ}} \log \mathrm{Ce}
$$

Where, $\mathrm{A}_{\mathrm{HJ}}$ and $\mathrm{B}_{\mathrm{HJ}}$ are constants and can be obtained from the plot of $1 / \mathrm{q}_{\mathrm{e}}{ }^{2}$ and $\log \mathrm{C}_{\mathrm{e}}$. The parameters obtained for different isotherms along with $\mathrm{R}^{2}$ value are presented in Table 1 .

\section{Jovanovich isotherm}

The model of an adsorption surface considered by Jovanovich is essentially the same as that considered by Langmuir. The Jovanovich equation can be used less in physical adsorption. It is applicable to mobile and monolayer localized adsorption without lateral interactions. This equation reduces to Henry's law at low concentration. At high concentration, it reaches the saturation limit. The Jovanovich equation has a slower approach toward the saturation than that of the Langmuir equation [35]. The Jovanovich model can be shown as Equation (9):

$$
\mathrm{Lnq}_{\mathrm{e}}=\mathrm{Lnq}_{\max }+\mathrm{K}_{\mathrm{f}} \mathrm{C}_{\mathrm{e}}
$$

where $\mathrm{q}_{\mathrm{e}}$ is quantity of adsorbated at equilibrium $\left(\mathrm{mg} \mathrm{g}^{-1}\right), \mathrm{q}_{\max }$ is maximum uptake of adsorbate obtained from the plot of $\ln \mathrm{q}_{\mathrm{e}}$ versus $\mathrm{C}_{\mathrm{e}}$, and $\mathrm{K}_{\mathrm{f}}$ is Jovanovic constant. The parameters obtained for different isotherms along with $\mathrm{R}^{2}$ value are presented in Table 1.

\begin{tabular}{|c|c|c|c|c|}
\hline \multirow{2}{*}{ Models } & \multirow{2}{*}{ Parameters } & \multicolumn{3}{|c|}{ Temperature } \\
\cline { 2 - 5 } & & $\mathbf{2 5}^{\circ} \mathbf{C}$ & $\mathbf{3 5} \mathbf{C}$ & $\mathbf{4 5}^{\circ} \mathbf{C}$ \\
\hline \multirow{3}{*}{ Freundlich } & $K$ & 409.5 & 350.5 & 236.7 \\
\cline { 2 - 5 } & $n$ & 0.73 & 0.55 & 0.47 \\
\cline { 2 - 5 } & $R^{2}$ & 0.9730 & 0.9859 & 0.9875 \\
\hline \multirow{4}{*}{ Langmuir } & $q_{m}\left(m g g^{-1}\right)$ & 153.8 & 26.5 & 16.7 \\
\cline { 2 - 5 } & $b 10^{3}$ & 1.97 & 11.45 & 18.16 \\
\cline { 2 - 5 } & $r$ & 0.941 & 0.750 & 0.702 \\
\cline { 2 - 5 } & $R^{2}$ & 0.9993 & 0.9998 & 0.9983 \\
\hline \multirow{3}{*}{ Dubinin-Radushkevich } & $q_{s}\left(m g g^{-1}\right)$ & 3.66 & 2.95 & 2.26 \\
\cline { 2 - 5 } & $E$ & 3.16 & 3.16 & 2.67 \\
\cline { 2 - 5 } & $R^{2}$ & 0.9607 & 0.9474 & 0.9336 \\
\hline \multirow{3}{*}{ Temkin } & $B_{l}\left(J \mathrm{~mol}^{-1}\right)$ & 0.46 & 0.67 & 1.06 \\
\cline { 2 - 5 } & $A\left(\mathrm{~L} \mathrm{mg}^{-1}\right)$ & 7.38 & 3.77 & 2.10 \\
\cline { 2 - 5 } & $R^{2}$ & 0.9904 & 0.9933 & 0.9971 \\
\hline \multirow{3}{*}{ Hurkin Jura } & $A_{H J}$ & 0.988 & 1.047 & 1.089 \\
\cline { 2 - 5 } & $B_{H J}$ & 1.109 & 1.543 & 0.300 \\
\cline { 2 - 5 } & $R^{2}$ & 0.9351 & 0.9419 & 0.9437 \\
\hline \multirow{3}{*}{ Jovanovich } & $q_{m}\left(\mathrm{mg} \mathrm{g}^{-1}\right)$ & 0.845 & 0.985 & 0.042 \\
\cline { 2 - 5 } & $K_{f}$ & 0.127 & 0.070 & 0.9951 \\
\cline { 2 - 5 } & $R^{2}$ & 0.9997 & 0.9980 & \\
\hline
\end{tabular}


Correlation coefficients of Table 1 are closer to unity in case of model Jovanovich. The results revealed that the adsorption isotherm models fitted the data in of Jovanovich and Langmuir isotherms more than Freundlich and Hurkins-Jura isotherms for the Methylene blue. This can allows to conclude that the adsorption of Methylene Blue with AOP/MA surface is localized monolayer adsorption and the adsorbent surface is homogeneous.

The adsorption is probably a physical process while the DubininRadushkevich model indicates a value of $E$ lower than $8 \mathrm{~kJ} \mathrm{~mol}^{-1}$ and the heat of sorption $\mathrm{B}_{1}$ of Temkin model is lower than $80 \mathrm{~kJ} \mathrm{~mol}^{-1}$ [36]. Similar results were also reported by several authors $[2,28,31,37]$ in order to the removal of Methylene Blue onto the different adsorbents composite with alginate.

\section{Kinetic study of dyes adsorption}

The kinetics of dyes adsorption on the magnetic alginate composite beads was analyzed using pseudo-first-order and pseudo-second-order kinetic models. A relatively high correlation coefficients $R^{2}$ value indicates that the model successfully describes the kinetics of dyes adsorption. The kinetic study was carried out with $100 \mathrm{~mL}$ of Methylene blue solution at $10 \mathrm{mg} \mathrm{L}^{-1}$ and $1 \mathrm{~g}$ of AOP/MA and at three temperatures 25 to $45^{\circ} \mathrm{C}$.

\section{Pseudo-first-order kinetics}

Lagergren showed that the rate of adsorption of solute on the adsorbent is based on the adsorption capacity and followed a pseudo-first-order equation [38] in Equation (10):

$$
\log \left(\mathrm{q}_{\mathrm{e}} \mathrm{-q}\right)=\mathrm{K}_{1} \mathrm{t} / 2.303
$$

where, $\mathrm{q}_{\mathrm{e}}$ and $\mathrm{q}$ are the amounts of dyes adsorbed $\left(\mathrm{mg} \mathrm{g}^{-1}\right)$ at equilibrium time and at any instant of time respectively. $\mathrm{K}_{1}\left(\mathrm{~L} \mathrm{~min}^{-1}\right)$ is the rate constant of the pseudo-first-order adsorption operation. The pseudo first order kinetics is presented in figure 4.

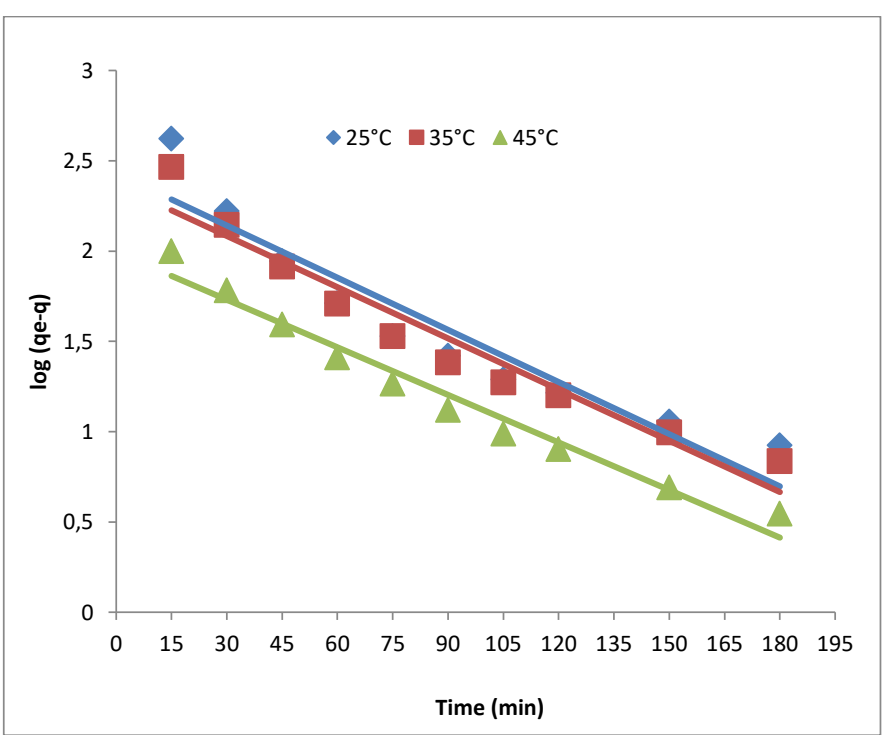

Figure 4. Pseudo-first-order plot.

The plot of $\log \left(\mathrm{q}_{\mathrm{e}}-\mathrm{q}\right)$ versus $\mathrm{t}$ gives a straight line for the pseudo-first-order adsorption kinetics, from which the adsorption rate constant, $\mathrm{K}_{1}$, is estimated.

\section{Pseudo-Second-order kinetics}

As pseudo-first-order kinetic model gives only $\mathrm{K}_{1}$ and as $\mathrm{q}_{\mathrm{e}}$ cannot be estimated using this model, applicability of the second order kinetics has to be tested for the estimation of $\mathrm{q}_{\mathrm{e}}$ with Equation (11):

$$
\mathrm{t} / \mathrm{q}=1 /\left(\mathrm{K}_{2} \mathrm{qe}^{2}\right)+1 / \mathrm{q}_{\mathrm{e}}
$$

where, $\mathrm{K}_{2}\left(\mathrm{~g} \mathrm{mg}^{-1} \mathrm{~min}^{-1}\right)$ is the pseudo-second-order rate constant. The plot of $\mathrm{t} / \mathrm{q}$ versus $\mathrm{t}$ should give a linear relationship, which allows the determination of $\mathrm{q}_{\mathrm{e}}$ and $\mathrm{K}_{2}$. The results are presented in the figure 5 .

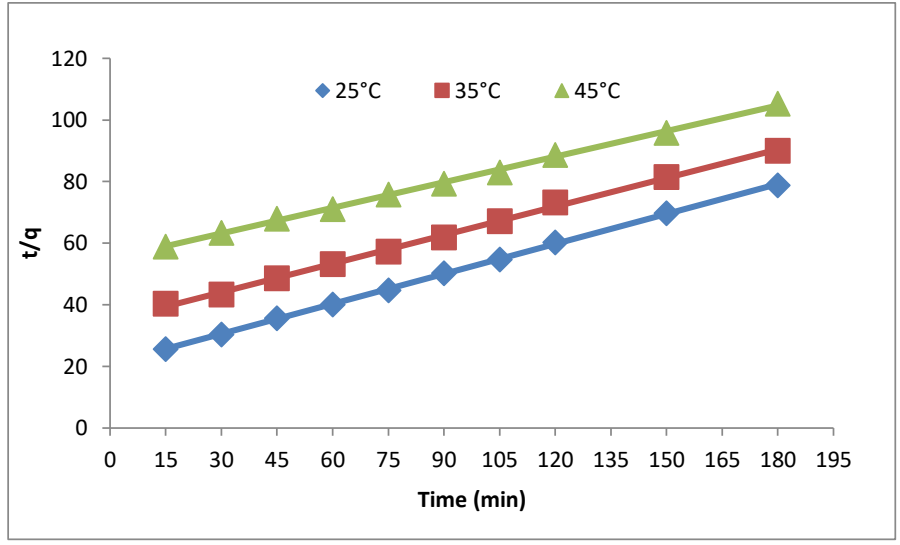

Figure 5. Pseudo-second-order plot.

The results of the kinetic study are presented in table 2 .

Table 2. Kinetic parameters for Lagergren models

\begin{tabular}{|l|c|c|c|c|}
\hline \multirow{2}{*}{ Models } & \multirow{2}{*}{ Parameters } & \multicolumn{3}{|c|}{ Temperature } \\
\cline { 2 - 5 } & & $\mathbf{2 5}^{\circ} \mathbf{C}$ & $\mathbf{3 5}^{\circ} \mathbf{C}$ & $\mathbf{4 5}^{\circ} \mathbf{C}$ \\
\hline \multirow{2}{*}{ Pseudo first order } & $k_{1}\left(\mathrm{~L} \mathrm{~min}^{-1}\right)$ & 0.022 & 0.021 & 0.020 \\
\cline { 2 - 5 } & $R^{2}$ & 0.8953 & 0.9379 & 0.9687 \\
\hline \multirow{2}{*}{ Pseudo second order } & $k_{2}\left(\mathrm{~g} \mathrm{mg}^{-1} \mathrm{~min}^{-1}\right)$ & 2.61 & 1.39 & 0.77 \\
\cline { 2 - 5 } & $R^{2}$ & 0.9997 & 0.9980 & 0.9985 \\
\hline
\end{tabular}

The correlation coefficients for the pseudo-second-order kinetic plots obtained at the studied temperatures were greater than the pseudo-first-order. These results show that the adsorption processes were in the pseudo-second-order reaction at 25,35 and $45^{\circ} \mathrm{C}$. A similar phenomenon has been observed for dyes adsorption on AOP/MA and showed that a pseudo-second-order kinetic equation is well suited for modeling the adsorption kinetic of dyes onto various adsorbents $[31,39]$.

\section{Regeneration studies}

The regeneration of adsorbent is a significant economic factor for the treatment process. It explains the mechanism of dye-loaded adsorbents for regeneration, recycling, and reusing of spent adsorbents to save money and the environment from secondary pollution [10]. For this reason the regeneration of used adsorbent was made with an $\mathrm{HCl}$ solution $\left(0.1 \mathrm{~mol} \mathrm{~L}^{-1}\right)$. There is no significant decrease in adsorption performance of AOP/MA beads with increasing regeneration cycles as a result of recovery of available active sites after the regeneration process (Figure 6).

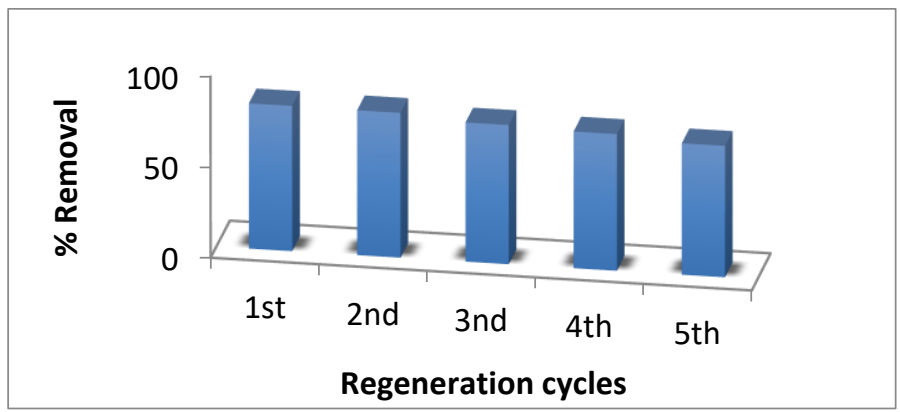

Fig 6. Regeneration test.

The reason might be that under acidic conditions the bioadsorbent surface was protonated by $\mathrm{H}_{3} \mathrm{O}^{+}$ions which enable desorption of positively charged Methylene Blue ions from AOP/MA beads surface [40] and let it clean for using in adsorption. The removal efficiencies were maintained at $72.5 \%$ using respectively $\mathrm{HCl}$ solution after five cycles. These values demonstrate that magnetic alginate composite beads offers sustainability for treatment of dyecontaining wastewater. 


\section{CONCLUSION}

A comparative study was performed with different adsorbents orange peels, orange peels activated, activated orange peels /Alginate and activated orange peels / Magnetic Alginate. Adsorption isotherm studies clearly indicated that the Langmuir and Jovanovich model showed a better fit for adsorption of dyes by AOP/MA beads, implying a monolayer/homogeneous binding surface. The D-R and Temkin model both indicated a physisorption process. Kinetic data of adsorption well fitted to pseudo-second order kinetic model. Finally, the removal efficiencies were maintained using $\mathrm{HCl}$ solution as desorbing agent after five cycles of adsorption-desorption. The study indicates the potential of AOP/MA beads to act as an effective adsorbent for removal of dyes from wastewaters.

\section{REFERENCES}

1. Aarfane, A.; Salhi, A.; El Krati, M.; Tahiri, S.; Monkade, M.; Lhadi, E.K.; and Bensitel, M. J. Mater. Environ. Sci. 5, 1927 (2014).

2. Benhouria, A.; Islam, M.A.; Zaghouane-Boudiaf, H.; Boutahala, M.; and Hameed, B.H. Chem. Eng. J. 270, 621 (2015).

3. Yao, Y.; Xu, F.; Chen, M.; Xu, Z.; and Zhu, Z. Bioresour. Technol.101, 3040 (2010).

4. Peng, Y.; Wang, K.K.; Liu, T.; Xu, J.; and Xu, B.G. Appl. Catal. B. 203, 946 (2017).

5. Pandey, A.; Singh, P.; and Iyengar, L. Int. Biodeter. Biodegr. 59, 73 (2017).

6. Canizares, P.; Martínez, F.; Jiménez, C.; Lobato, J.; and Rodrigo, M.A. Environ. Sci. Technol. 40, 6418 (2006).

7. Arslan, İ.; Balcioğlu, A.D.; and Bahnemann, D.W. Dyes. Pigm., 47, 207 (2000).

8. Al-Bastaki, N. Chem. Eng. Process. 43, 1561 (2004).

9. Liu, Q.; Yang, B.; Zhang, L.; and Huang, R. Inter. J. Biol. Macromol. 72, 1129 (2015)

10. Oladipo, A.A.; and Gazi, M. J. Water. Process. Eng. 2, 43 (2014).

11. Peng, Q.; Liu, M.; Zheng, J.; and Zhou, C. Micropor. Mesopor. Mat. 201, 190 (2015).

12. Kyzas, G.Z.; Lazaridis, N.K.; and Mitropoulos, A.Ch. Chem. Eng. J. 189, 148 (2012).

13. Zeng, G.; Min, C.; Danlian, H.; Cui, L.; Piao, X.; Zhen, W.; Ningjie, L.; Chen, Z.; Xiaoxiao, H. and Yan, H. Waste. manage. 4, 424 (2015).

14. Giannakoudakis, D.A.; Kyzas, G.Z.; Avranas, A.; and Lazaridis, N.K. J. Mol. Liq. 213, 381 (2016).

15. Aichour, A.; Zaghouane-Boudiaf, H.; Iborra, C.V. and Polo, M.S. J. Mol. Liq. 256, 533 (2018).

16. Hassani, A.; Soltani, R.D.C.; Karaca, S.; and Khataee, A. J. Ind. Eng. Chem. 21, 1197 (2015)

17. Jost, V.; Kobsik, K.; Schmid, M.; and Noller, K. Carbohydr. Polym. 110, 309 (2014).

18. Pankhurst, Q. A.; Connolly, J.; Jones, S. K.; Dobson, J. J. Phys. D Appl. Phys. 36, 167 (2003).

19. Martin, C. R.; Mitchell, D. T. Anal. Chem. 70, 322 (1998).

20. Rocher, V.; Siaugue, J.M.; Cabuil, V.; and Bee, A. Water. Res. 42, 1290 (2008).

21. Fan, L.; Luo, C.; Sun, M.; Qiu, H.; and Li, X. Colloids. Surf. B. 103, 601 (2013).

22. Travlou, N.A.; Kyzas, G.Z.; Lazaridis, N.K.; and Deliyanni, E.A. Langmuir 29, 1657 (2013)

23. Elwakeel, K.Z.; El-Bindary, A.A.; El-Sonbati, A.Z.; and Hawas, A.R. Can. J. Chem. 95, 807 (2017).

24. Sun, L.; Chen, D.; Wan, S.; and Yu, Z. Bioresour. Technol. 198, 300 (2015).

25.Zakaria, Z.A.; Suratman, M.; Mohammed, N.; and Ahmad, W.A. Desalination. 244, 109 (2009).

26. Nasrullah, A.; Bhat, A.H.; Naeem A.; Isa, M.H.; and Danish, M. Int. J. Biol. Macromol. 107,1792 (2019).

27. Ravi, R.; and Pandey, L.M.; Appl. Clay Sci. 169, 102 (2019)

28. Alves, D.C.L.; Yáñez-Vilar, S.; Piñeiro-Redondo, Y.; and Rivas, J. Nanomaterials. 9, 356 (2019).

29. [29] Afroze, S.; Sen T.; Ang, H. M.; Nishioka, H. Desalin. Water. Treat. 57, 1 (2015).

30. Shakoor, S.; Nasar, A. J. Taiwan. Inst. Chem. E. 66, 154 (2016).

31. Hassan, A.F.; Abdel-Mohsen, A.M.; and Fouda, M.M.G. Carbohydr. Polym. 102,192 (2014).

32. Saadi, R.; Saadi, Z.; Fazaeli, R.; and Fard, N.E. Korean. J. Chem. Eng. 32, 787 (2015).

33. Malik, P.K. J. Hazard. Mater. 113, 81 (2014).

34. Hosseinia, M.; Mertensb, S.F.L.; Ghorbanic, M.; and Arshadi, M.R. Mater. Chem. Phys. 78, 800 (2003).
35. Jovanovich, D.S. Colloid Polym. Sci., 2351203 (1969).

36. Inglezakisa, V.J.; and Zorpas, A.A. Desalin. Water. Treat. 39, 149 (2012).

37. Auta, M. and Hameed, B.H. J. Ind. Eng. Chem. 19, 1153 (2013).

38. Ho, Y.S.; and Mckay, G. J. Environ. Sci. Health. A34, 1179 (1999).

39. Azizian, S.; Haerifar, M.; and Bashiri, H. Chem. Eng. J. 146, 36 (2009).

40. Bhatti, H.N.; Zaman, Q.; Kausar, A.; Noreen, S.; and Iqbal, M. Eco.l Eng. 95 , 216 (2016). 